\title{
A constituição da profissão dos enfermeiros em Portugal. A Escola de Enfermagem de Castelo Branco (1948-1988)
}

The constitution of the nurse profession in Portugal. The Nursing School of Castelo Branco (1948-1988)

\author{
António Gomes Ferreira \\ Universidade de Coimbra \\ Helder Manuel Guerra Henriques \\ Instituto Politécnico de Portalegre
}

\section{Resumo}

Este trabalho pretende interpretar o processo de construção do grupo profissional dos enfermeiros portugueses, entre os anos de 1940 e 1980 do século XX. Partimos da discussão conceptual sobre o papel formativo e credencialista das instituições escolares de enfermagem, em articulação com o Estado, para compreender a construção identitária deste grupo, caraterizando os sujeitos que frequentaram a Escola de Enfermagem de Castelo Branco/Dr. Lopes Dias (Portugal), no arco temporal previsto. A metodologia assumida na construção deste artigo é a análise sócio-histórica, numa perspetiva diacrónica. A História da Educação e a Sociologia das Profissões constituem os principais domínios científicos em que o trabalho assenta.

Palavras-chave: Formação. Credencialismo. Enfermagem. Estado

\section{Abstract}

This work intends to interpret the development process of nurses professional group, between 1940's and 1980's. We set out from the conceptual discussion on the formative and credencialist role in schools of nursing, in conjunction with the role of State, to understand the identity construction of this group featuring the subjects who attended nursing school of Castelo Branco/Dr. Lopes Dias (Portugal). The methodology adopted in the construction of this article is a socio-historical analysis in a diachronic perspective. The history of Education and the Sociology of Professions are the main scientific areas in which this work is based.

Keywords: Training. Credentialism. Nursing. State. 


\section{Introdução}

A História da Educação, em articulação com outros domínios do Saber e através de meios analíticos próprios, tem vindo a estudar gradualmente a problemática das configurações identitárias coletivas. Uma leitura devidamente fundamentada sobre este assunto constitui uma valia relevante para a compreensão global da sociedade contemporânea. $\bigcirc$ propósito deste artigo prende-se precisamente com a construção identitária de um grupo profissional português, na segunda metade do século XX (1948 - 1988). Estamos a referir-nos ao grupo da enfermagem que foi alcançando, no arco temporal indicado, um estatuto social e profissional mais reconhecido à medida que nos aproximamos do final do milénio passado. Os estudos que abordam estas questões são ainda escassos, nomeadamente no interior da História da Educação, tornando este trabalho, desejavelmente, um contributo científico capaz de discutir e abordar novos aspetos da problemática anunciada, relacionando as identidades e a construção dos grupos profissionais, assumindo como elemento condutor desta abordagem o papel das instituições de formação na produção de identidades profissionais.

Para o efeito colocamos as seguintes questões de partida: Quem eram os profissionais que praticavam a enfermagem em Portugal? Quem eram os enfermeiros portugueses? Qual era a sua origem socioeconómica? Como o recrutamento e a formação terão influenciado o processo de construção identitária dos enfermeiros portugueses? Que papel assumiu o Estado neste contexto?

Para tentarmos responder e objetivar melhor as questões colocadas recorremos ao caso da Escola de Enfermagem de Castelo Branco/Dr. Lopes Dias. O recurso a esta instituição escolar implica, desde logo, algumas considerações prévias que podem influenciar de alguma forma a leitura sobre a construção identitária dos enfermeiros ali formados. Em primeiro lugar, esta escola situava-se numa zona do interior de Portugal, perto da fronteira com Espanha, afastada da capital e dos grandes centros urbanos; em segundo lugar, esta escola, até 1973, era de natureza particular, passando a partir desse ano a escola oficial; em terceiro lugar, esta era uma instituição de formação de enfermeiros pequena, em comparação com outras congéneres situadas nos grandes centros urbanos. Todavia, em nosso entender, a Escola de Enfermagem de Castelo Branco/Dr. Lopes Dias segue claramente as orientações gerais do Estado, do ponto de vista da seleção dos candidatos a alunos 
de enfermagem e, por isso mesmo, constitui um exemplo a ter em conta quando analisamos os processos de construção identitária deste grupo.

Porque se trata de olhar para uma instituição de ensino e para a formação de enfermeiros, o presente trabalho encontra o seu vínculo teórico na História da Educação (NÓVOA, 1987; LAWN, 2001; Ó \& CARVALHO, 2009; FARIA FILHO, 201 2; HENRIQUES, 201 2; HENRIQUES \& FERREIRA, $2012 a$; HENRIQUES \& FERREIRA, 2012) em articulação com a Sociologia das profissões (FREIDSON, 1986; ABBOTT, 1988; LONGUENESSE, 1994; MACDONALD, 1995; RODRIGUES, 1999; FOLGADO, 2006) e com alguma literatura especializada dos próprios enfermeiros portugueses ICOLLIERE, 1989; SOARES, 1997; ABREU, 2001; NUNES, 2003; ESCOBAR, 2004; AMENDOEIRA, 2006) que se debruçaram sobre a sua história profissional. Do ponto de vista empírico utilizamos principalmente fontes documentais: 1) a legislação publicada sobre a enfermagem entre os anos de 1940 e 1980 do século XX; 2) os processos biográficos de antigos alunos da instituição escolar; 3) diversos materiais de arquivo (Livros de correspondência, Livros de matrícula, fichas clínicas, por exemplo). Obviamente, as principais fontes relacionam-se com a Escola de Enfermagem de Castelo Branco/ Dr. Lopes Dias uma vez que é sobre esta instituição escolar que mais incidiremos na compreensão da construção de identidades dos/as enfermeiros/as, logo dando especial destaque ao recrutamento dos alunos/as e à origem social deles. A análise sociohistórica foi privilegiada dado que permite a interpretação dialética de um conjunto de aspetos que possibilitam uma compreensão ampla sobre o assunto em análise. $\bigcirc$ artigo divide-se em quatro partes relacionadas entre si. Iniciamos com uma abordagem teórica ancorada na História da Educação e na Sociologia das profissões. No segundo momento é analisado o processo de recrutamento dos enfermeiros portugueses no arco temporal previsto. Depois, faremos uma breve abordagem do percurso histórico da Escola albicastrense. E, por fim, apresentamos, com detalhe, as origens sociais e económicas dos alunos da Escola de Enfermagem de Castelo Branco/ Dr. Lopes Dias entre 1948 e 1988. 


\section{O Estado, a Formação e a Construção de Identidades Profissionais}

A fabricação de identidades constitui um campo vasto de análise, encontrando-se relacionado com um conjunto de elementos que influenciam o reconhecimento social e profissional das ocupações que procuram afirmar e constituir-se como atividades profissionais. As instituições escolares e formativas assumem uma importância assinalável no processo de construção das identidades profissionais enquanto elementos credencialistas e controladores da entrada de indivíduos para as profissões, representando o Estado nesse mesmo processo seletivo. Neste sentido, defendemos que o Estado exerce um papel relevante na construção das identidades profissionais na contemporaneidade, através dos processos formativos e institucionais.

A relação entre o Estado e as atividades profissionais constitui um importante eixo analítico uma vez que o primeiro soube utilizar as profissões de modo a garantir a edificação de uma ideia de Estado-Nação enquanto elemento administrador, governador e controlador das populações. (LONGUENESSE, 1994). O projeto político do Estado alcançou enorme 10 visibilidade através das profissões, pois os grupos profissionais eram recompensados pela sua eficiência e desempenho constituindo-se, deste modo, uma relação de cumplicidade, dependência e transformação das relações sociais. Por esta via, o Estado apresenta-se como um elemento ativo na promoção e transformação de algumas ocupações, como a enfermagem, em atividades de carater profissional.

Para potenciar esta relação, o Estado soube criar privilégios para os grupos que melhor possibilitaram a sua presença na sociedade. Muitas vezes os coletivos acabavam por cair na dependência do Estado e eram assim, também, controlados. Quer dizer, se por um lado o Estado necessitava das profissões para controlar e administrar a sociedade, por outro lado as atividades profissionais pretendiam afirmar-se na sociedade e olhavam para 0 Estado como um elemento promotor de reconhecimento socioprofissional. As profissões ganham importância se o Estado as reconhecer como tal e o Estado reforça o seu poder ao colocar-se na posição de legitimador da capacidade de ação de um coletivo de pessoas.

Esta leitura assume particular pertinência quando analisamos os processos de construção identitários das atividades profissionais. Por isso, 
as profissões constituem um elemento central no desenvolvimento do Estado moderno como sujeito de intervenção na sociedade, por exemplo, por via das instituições escolares. Em regra, é o Estado que coloca em evidência os requisitos que um determinado candidato deve possuir quando pretende ingressar num grupo. As orientações do Estado não se ficam apenas pelas habilitações literárias necessárias ao ingresso. Ultrapassam muito esta necessidade. $\bigcirc$ Estado, em certas alturas com maior evidência, legisla sobre o corpo dos candidatos, a performance que devem possuir, a matriz psicológica ou a sua vida privada. (Ó \& CARVALHO, 2008). Esta incursão tem como objetivo identificar, selecionar e controlar os elementos que pretendem o ingresso nos grupos. Às escolas, e aos atores educativos como os professores, diretores ou os médicos escolares, cabe o papel de validar esses candidatos à luz das orientações do Estado. A seleção continua ao longo da sua presença nas instituições escolares, através dos processos de socialização profissional ou mesmo das provas de aferição de conhecimentos escolares teóricos ou práticos onde, em especial nos últimos, a vigilância é bastante acentuada (por exemplo, os estágios pedagógicos ou clínicos etc.).

Oexercício de poder por parte do Estado junto da população escolar pode ser objetivada a partir do conceito de credencialismo. Este conceito apresenta-se como uma lente que permite observar o Estado em ação através da atribuição de licenças ou mandatos que possibilitam os indivíduos, depois de passarem por um conjunto de elementos de avaliação e seleção, exercer determinadas atividades legalmente no interior da sociedade. No caso da enfermagem é recorrente encontrarmos este tipo de discurso nos órgãos próprios de circulação de ideias. Logo no $1^{\circ}$ número da Revista de Enfermagem, se dava conta de que: "[...] a profissão de enfermagem, é uma profissão nobre, é mesmo uma profissão sublime, mas só quando exercida pelos verdadeiros profissionais, e nunca por "enfermeiros furtivos», ou antes, amadores aventureiros." (BRANCO, 1953, p. 21 ).

Ou seja, sentiam os enfermeiros que era preciso reservar o serviço de enfermagem só a quem fosse reconhecida a formação para isso. De acordo com a abordagem sociológica interacionista o conceito de licença e/ou mandato constituem a base da divisão moral do trabalho, na medida em que orientam a seleção dos profissionais. (RODRIGUES, 2002). A licença consiste na autorização legal que permite o exercício de atividades, restringindo o acesso a outros; o mandato, segundo Joaquim Folgado (2006, p. 26), é a "[... ] 
correlativa obrigação de prestar esse serviço à sociedade, num espírito desinteressado, como que "de missão", e sujeito a regras de conduta rigorosas." A enfermagem constitui um exemplo interessante que potencia e dá substância aos conceitos referidos e definidos anteriormente. Estes conceitos ajudam a construir a ideia de credencialismo que pode caracterizar-se, em parte, por esse ato de subordinação, ao mesmo tempo habilitador e de reconhecimento das capacidades dos indivíduos que, para exercer algumas atividades profissionais, deveriam possuir determinadas "qualidades" definidas por um poder.

$\bigcirc$ Estado assume um papel central na construção das identidades profissionais, uma vez que é ele que influencia mais diretamente a fabricação de identidades de acordo com os seus interesses estratégicos no interior da sociedade. Isto aconteceu com vários grupos profissionais. As orientações do Estado, umas vezes mais diretivas que outras, caraterizam-se como uma força centrípeta e construtora de identidades profissionais, adaptadas aos contextos políticos e às épocas e necessidades reveladas pela sociedade.

Os processos de seleção e formação dos indivíduos constituem o elemento que se cruza com tudo aquilo que dissemos até agora e que ajudam na construção identitária das atividades profissionais. As escolas oficiais, ou par-

12 ticulares, assumem um papel de grande interesse uma vez que são elas a face mais visível de todo o exercício de poder do Estado e objetivam o processo credencialista que temos vindo a caraterizar. A formação escolar constitui um elemento importante no processo de construção do conhecimento que permite às ocupações transformarem-se em profissões, com um território próprio ou um domínio científico concreto, mais ou menos reforçado consoante o desenvolvimento, mais ou menos avançado, do seu conhecimento aplicado e reconhecido pela sociedade, pelo Estado e pelos grupos profissionais próximos.

\section{O Recrutamento nas Escolas de Enfermagem: enquadramento legal}

A partir de finais do século XIX a enfermagem inicia um processo de emergência e afirmação de natureza profissional. Este processo é acompanhado pela fundação das primeiras escolas dedicadas ao ensino de enfermagem em Portugal, nos centros urbanos como Coimbra, Lisboa ou Porto. Estas escolas foram fundadas por médicos ou eram controladas por membros 
deste grupo profissional. Até aos anos de 1940 do século XX, as escolas de enfermagem portuguesas encontravam-se ou na dependência de congregações religiosas (nomeadamente na década de 30) ou dependentes das administrações hospitalares.

Nos alvores dos anos de 1940 da centúria passada, a situação que caraterizamos atrás altera-se em grande medida pelo interesse manifestado pelo Estado em legislar sobre o grupo dos enfermeiros portugueses. Se, até essa altura, o ser enfermeiro dependia de se ser admitido como tal nos hospitais portugueses, a partir de então o Estado vai começar a valorizar mais o papel das escolas de enfermagem no processo de seleção dos candidatos ao curso de Enfermagem e, consequentemente, na futura composição do grupo dos enfermeiros portugueses.

A partir de 1942, o exercício da enfermagem em Portugal ficou dependente da aquisição de um diploma, iniciando-se um "combate" aos "enfermeiros furtivos", isto é sem habilitação legal e escolar. Este constitui, portanto, um marco no processo de valorização da enfermagem e de reconhecimento da sua importância na sociedade e utilidade para o Estado.

Os anos de 1940 e seguintes revelaram-se especialmente produtivos no que respeita ao ensino e exercício da enfermagem portuguesa. Além das regras colocadas pelo diploma de 1942, em 1947 surge um outro diploma de muito interesse para a enfermagem. A reforma desse ano propunha-se combater a falta de mão-de-obra desta atividade, criando, entre outros, os cursos de pré-enfermagem e auxiliares de enfermagem.

A criação destes cursos influenciou o desenvolvimento da atividade pela negativa. Sobretudo o de auxiliares de enfermagem, caraterizava-se por ser um curso: com a entrada facilitada do ponto de vista literário (instrução primária); ser menos exigente e de menor duração (1 ano/ 1 ano e meio). Ora, a criação destes cursos acabou por constituir um entrave ao desenvolvimento da enfermagem como profissão, dado que a existência de vários cursos associados à enfermagem dificultava o reconhecimento socioprofissional que a atividade e o grupo precisavam. Mesmo assim, em 1952, o Estado legislou no sentido de aumentar o número de anos do curso de Enfermagem Geral (três anos), acabando por afastar ainda mais público deste curso, que escolhia o curso de Auxiliares de Enfermagem, mais simples, curto e fácil, permitindo rapidamente a entrada no mercado de trabalho. 
As habilitações literárias necessárias para aceder às escolas de enfermagem para o curso de Auxiliares de Enfermagem eram, até 1965, a instrução primária e para o curso de Enfermagem Geral o $1^{\circ}$ ciclo dos liceus. Estas baixas habilitações obrigaram á introdução de um Exame de Aptidão que era essencialmente literário e composto pelas matérias da instrução primária para o curso de Auxiliares de Enfermagem e matérias dos programas do ensino liceal para os candidatos ao curso de Enfermagem Geral. Este exame terminou em 1970, na sequência das remodelações provocadas pela legislação de 1965.

A reforma de 1965, além de colocar definitivamente o ensino da enfermagem nas mãos dos próprios enfermeiros, aumentou as exigências literárias. No caso dos Auxiliares de Enfermagem o requisito passou a ser o $1^{\circ}$ ciclo dos liceus, enquanto o $2^{\circ}$ ciclo dos liceus seria o exigido para o curso de Enfermagem Geral. Este processo seria novamente revisto em 1979, quando o curso de Enfermagem Geral passa a ter como requisito literário o curso complementar dos liceus e, já na década de 80 (1988), vai ser exigido o $12^{\circ}$ ano de escolaridade ou equivalente a quem se quisesse candidatar ao curso de Enfermagem.

Os candidatos às escolas de enfermagem, entre os anos de 1940 e 141980 do século XX, deviam possuir, além dos requisitos literários, qualidades físicas para a sua integração na escola, como sejam: estatura física (no Estado Novo era exigida uma altura de 1,50m para o sexo feminino e 1,55m para o sexo masculino), não sofrer de qualquer anomalia física ou psicológica, nem de doenças infeto contagiosas ou mesmo, durante o regime salazarista, "mau aspeto". Ao longo do período em análise percebemos que a vigilância sobre o corpo dos candidatos era realizada por especialistas médicos que preenchiam, para cada candidato, uma ficha clínica onde constavam um conjunto de requisitos que os candidatos a aluno não podiam evidenciar.

Na Escola de Enfermagem de Castelo Branco/Dr. Lopes Dias essas fichas clínicas foram utilizadas até aos anos de 1980 do século passado. Na verdade, entre a fundação da escola em 1948, pelo médico José Lopes Dias, e a integração da enfermagem no sistema educativo nacional em 1988, existiram três modelos de fichas aplicadas na instituição escolar. À medida que avançamos no tempo percebe-se que as fichas ganharam maior profundidade e procuravam conhecer o candidato fisicamente mas também o historial clínico dos seus parentes. É a procura da anormalidade que se encontra aqui em causa, evidenciando claramente que o Estado pretendia que a enfermagem 
se constituísse como uma espécie de profissão modelo, que serviria de exemplo para a sociedade. Esta ideia é especialmente notória no Estado Novo. A partir de meados dos anos de 1970 a enfermagem ganha outro impulso, fruto das organizações sindicais, da aproximação a novos saberes e da emergência e consolidação de uma nova ideia de Estado: o Estado-Providência que potenciou, não inocentemente, as atividades relacionadas com o Ser Humano, como os enfermeiros e os assistentes sociais, entre outros.

No Estado Novo realçava-se ainda outra característica que os candidatos deviam evidenciar e comprovar. Todos deviam possuir um comportamento moral irrepreensível. A forma de comprovar este comportamento era através de uma certidão comprovativa que um elemento "ilustre", normalmente médicos, párocos e professores/as, da sua localidade podia escrever. A partir do princípio dos anos de 1970, todo o processo de recrutamento altera-se. Há um processo de acompanhamento do aluno mais atento, menos disciplinador $e$, mais integrador.

As Comissões de Integração Escolar procuravam incentivar os alunos no seu processo de inclusão escolar, orientação profissional e académica e promover a sua autonomia. Estas comissões procuravam aferir as apetências dos alunos promovendo uma orientação profissional de proximidade através de especialistas com formação específica, como, por exemplo, os psicólogos. As Comissões de Integração Escolar passaram a desenvolver um importante papel nas questões relacionadas com os problemas de natureza disciplinar, orientando, do ponto de vista educativo as/os alunas/os e incutindo princípios de ordem deontológica ou ética, apelando à autonomia do próprio educando e substituindo a natureza moral da atividade profissional que o Estado Novo defendera, ao longo dos anos de 1940, 1950 e 1960.

A revolução de 1974 trouxe um conjunto de alterações que acentuam uma nova visão na forma de encarar a gestão das escolas de enfermagem portuguesas. Pretendia-se uma gestão participativa, integradora e democrática. A partir de 1976 a preocupação com a seleção dos candidatos era evidente com as organizações sindicais a pretenderem ver esclarecido este assunto. Gerou-se alguma confusão e constitui-se, para o efeito, o projeto de Diagnóstico e Conselho Vocacional para Admissão ao Curso de Enfermagem (DICOVE) que pretendia estudar e propor um processo de seleção dos alunos a partir dos contributos fornecidos pelas diferentes escolas de enfermagem. relatório foi concluído em 1986, todavia, numa altura em que se esperava 
essencialmente pela integração da enfermagem no ensino superior, o projeto não teve praticamente efeito.

Nos anos de 1980 outros ventos sopraram, constituindo-se a enfermagem a partir de um curso do ensino superior, integrado no subsistema do ensino superior politécnico português. Estes elementos constituem um filtro importante que acabavam por influenciar o processo de construção da identidade dos indivíduos e do grupo e o seu próprio desenvolvimento enquanto atividade profissional. De facto, se no Estado Novo se pretendia sobretudo formar auxiliares de médicos, subservientes e sem autoridade, a partir do início dos anos de 1970, do século XX, pretende-se que o grupo encontre novas formas de valorização de modo a constituir uma jurisdição profissional forte e reconhecida. Mas, todos estes aspetos ganham maior objetividade se olharmos para aqueles que entravam nas escolas e apresentarmos o seu perfil académico e origem social.

\section{A Escola de Enfermagem de Castelo Branco/Dr. Lopes Dias: um retrato breve}

A Escola de Enfermagem de Castelo Branco foi fundada, em 1948, pelo médico José Lopes Dias na sequência da reforma do ensino da enfermagem de 1947. Este médico interessou-se pelas questões da assistência no espaço rural, desenvolvendo, desde a década de 30 do século XX, atividades de assistência no Dispensário de Puericultura Dr. Alfredo da Mota. Nesta mesma década ocupou também o cargo de médico escolar no Liceu Nuno Álvares, em Castelo Branco, preocupando-se com os problemas respiratórios dos estudantes e com o seu desenvolvimento físico e psicológico. Todavia, foi nos anos de 1940 que aplicou os seus conhecimentos académicos e pessoais para tentar criar uma faculdade de medicina na cidade. O objetivo não foi alcançado. Não perdendo de vista as questões assistencialistas, educativas e a importância de assegurar condições sanitárias e de saúde física e moral aos albicastrenses (habitantes de Castelo Branco) resolveu, com o apoio do Estado, fundar a Escola de Enfermagem.

A escola, de natureza particular, possuía autonomia técnica e administrativa. $\bigcirc$ seu funcionamento encontrava-se dependente de receitas atribuídas pelo orçamento do Dispensário de Puericultura Dr. Alfredo da Mota; de 
propinas (taxas) pagas pelos alunos; de eventuais subsídios concedidos pelo município ou outras entidades locais; de donativos particulares ou de subsídios do Estado. As questões económicas marcaram fortemente o próprio ensino praticado escola, uma vez que o seu diretor muitas vezes pretendia responder às solicitações dos professores e não podia devido aos problemas de natureza financeira que caraterizaram a instituição escolar enquanto estabelecimento particular. Apesar destas dificuldades, a Escola de Enfermagem de Castelo Branco manteve-se em funcionamento, entre 1948 e 1973, com enorme vontade de vingar e alcançar cada vez mais prestigio, resultado da importância deste projeto para o seu diretor e fundador e todo o corpo docente e alunos.

A organização administrativa da instituição até aos anos de 1970 caraterizava-se essencialmente pela existência de três órgãos mas a figura central da organização era o diretor.

\section{|lustração 1}

Organigrama com a matriz organizativa da Escola de Enfermagem de Castelo Branco entre 1948 e 1973

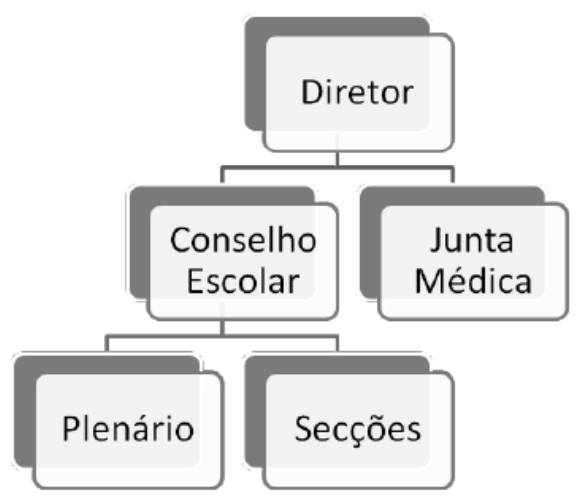

Entre 1948 e 1973 o diretor foi sempre o mesmo - José Lopes Dias. De acordo com os primeiros estatutos da Escola de Enfermagem (1948), cabia ao diretor a orientação, elaboração e fiscalização de todos os assuntos relacionados com o ensino, os serviços da escola, as questões pedagógicas, as contratações de pessoal, a admissão dos candidatos à escola, a submissão de 
tudo quanto fosse necessário ao Ministério do Interior, a disciplina e todas as questões de natureza económica.

Conselho escolar, presidido pelo diretor da instituição, era constituído por todos os professores da escola. As suas competências eram essencialmente pedagógicas: todos os assuntos que o diretor solicitasse deviam ser alvo de parecer deste órgão; a admissão a exames finais dos alunos também era sua competência, bem como a aplicação da pena de expulsão de alunos da instituição escolar. Este órgão podia reunir em plenário ou por secções, como evidenciamos na ilustração anterior. Cada secção correspondia a cada um dos cursos existentes na escola (Enfermagem Geral; Auxiliares de Enfermagem, etc.). Os interesses gerais da escola eram debatidos neste órgão colegial mas este era completamente controlado pela figura do diretor.

A Escola de Enfermagem de Castelo Branco/Dr. Lopes Dias possuía ainda um outro importante órgão: a Junta Médica. Esta junta era constituída pelo diretor, que presida, e por dois professores médicos. A junta médica assumia um papel central no processo de admissão dos candidatos aos cursos de enfermagem. Na verdade, nela se apoia uma lógica credencialista, porque nela se ancorava o poder que os médicos possuíam no processo de verifica18 ção das capacidades dos indivíduos para virem a tornar-se membros do grupo dos enfermeiros. Na prática cabia à Junta Médica examinar os candidatos ao exame de aptidão e à matrícula nas escolas de enfermagem; vigiar o estado sanitário dos alunos; vacinar e requisitar os exames médicos bem como as análises necessárias e verificar a doença dos alunos que tivessem ficado doentes.

Como já referimos, o início e o decorrer dos anos de 1970 trouxeram um conjunto de transformações para a enfermagem portuguesa. A estas transformações não foram alheias as escolas de enfermagem. Também a Escola de Enfermagem de Castelo Branco/Dr. Lopes Dias participou neste processo de mudança, embora com algumas especificidades. Aos poucos o ensino da enfermagem ganhava prestígio e o grupo consolidava-se. Já não servia o estatuto de Auxiliar de Médico, era preciso consolidar uma jurisdição profissional própria encontrando alternativas ao modelo de aprendizagem centrado nos conhecimentos médicos.

A partir de 1973 a Escola de Enfermagem de Castelo Branco/Dr. Lopes Dias tornou-se pública e foi constituída uma comissão instaladora que continuou a ser presidida pelo fundador da escola. A escola deveria seguir as 
regras gerais de funcionamento das instituições desta natureza cumprindo a legislação definida pelo governo. Com o estalar da revolução de 1974 tentaram implementar-se valores com matriz democrática, inclusivamente ao nível da gestão da própria escola ${ }^{1}$.

A escola passa a ser bastante marcada pelas relações pessoais e pela proximidade entre professores, alunos e funcionários, colocando a dimensão legal um pouco à margem do funcionamento real e concreto da escola. Ismael Martins, que dirigiu a Escola de Enfermagem de Castelo Branco/Dr. Lopes Dias durante este período de consolidação do Portugal democrático, refere-se à escola como uma família, o que, segundo ele, facilitava o próprio ensino da enfermagem, ajudando a desenvolver uma identidade profissional nos alunos tendo como base a humanização das suas tarefas enquanto futuros enfermeiros de acordo com um modelo formativo mais centrado na pessoa.

Este modelo formativo que a Escola de Enfermagem de Castelo Branco/Dr. Lopes Dias seguiu assentou essencialmente, por um lado, no domínio de conhecimentos técnicos, por outro, na importância de ferramentas relacionadas com a comunicação e na capacidade do enfermeiro observar e relacionar-se com o Ser Humano. Este tipo de competências identificadas permitiram ao grupo dos enfermeiros adquirir maior reconhecimento social, profissional e académico uma vez que assumiu o domínio da sua própria ação e do conhecimento que the era necessário. A integração das escolas de enfermagem no ensino superior é um momento que traduz o corolário de uma formação que transformou uma ocupação numa profissão relacional complexa.

\section{Os alunos da Escola de Enfermagem de Castelo Branco}

As escolas de enfermagem assumiram um importante papel na construção do grupo profissional dos enfermeiros. Também a Escola de Enfermagem de Castelo Branco participou no movimento que promoveu a edificação de um determinado estatuto socioprofissional do grupo. Podemos caraterizar este estatuto de acordo com dois aspetos: por um lado, a influência do Estado na objetivação do credencialismo, levado a efeito pelas instituições escolares, através das lógicas de recrutamento; por outro lado, a instituição escolar le o território onde se encontra instalada) geradora de oportunidades de mobilidade social, embora este aspeto se traduza em dificuldades acrescidas ao processo 
de desenvolvimento profissional global do grupo devido às características que apresentaremos a seguir. Assim, consideramos que as configurações profissionais dos grupos são determinadas pela existência de uma multiplicidade de escolhas e de pressões produzidas pelo meio envolvente no indivíduo/ grupo e na consequente necessidade de desenvolver determinadas estratégias coletivas num processo dinâmico e de constante de negociação. (ABBOTT, 1988). Assume-se, portanto, que estes dois eixos podem ser evidenciados a partir do exemplo dos alunos que passaram pela Escola de Enfermagem de Castelo Branco/Dr. Lopes Dias, entre 1948 e 1988. O recrutamento e a frequência desta instituição escolar constituem um exemplo capaz de contribuir para uma melhor interpretação do processo de profissionalização dos enfermeiros portugueses.

Ao longo dos anos de 1950 e 1960 as escolas de enfermagem formaram maioritariamente Auxiliares de Enfermagem. $\bigcirc$ Gráfico 1 permite estabelecer uma comparação entre o número de matriculados e diplomados em ambos os cursos. Da leitura geral do gráfico emerge uma conclusão inequívoca: a escola, que tinha como objetivo principal a formação de enfermeiros, tornou-se numa instituição essencialmente de formação de auxiliares 20 de enfermagem. Este aspeto é de uma enorme relevância, uma vez que os desenvolvimentos profissionais do grupo dos enfermeiros, cujas instituições escolares tinham um papel central no processo de acreditação socioprofissional do grupo, submeteram-se aos interesses gerais do regime político vigente e acrescentaram dificuldades ao já complexo processo de elevação profissional da enfermagem portuguesa. 


\section{Gráfico 1}

Evolução geral do número de alunos/as matriculados/as/Diplomados/as na Escola de Enfermagem de Castelo Branco/Dr. Lopes Dias (1948-1988)

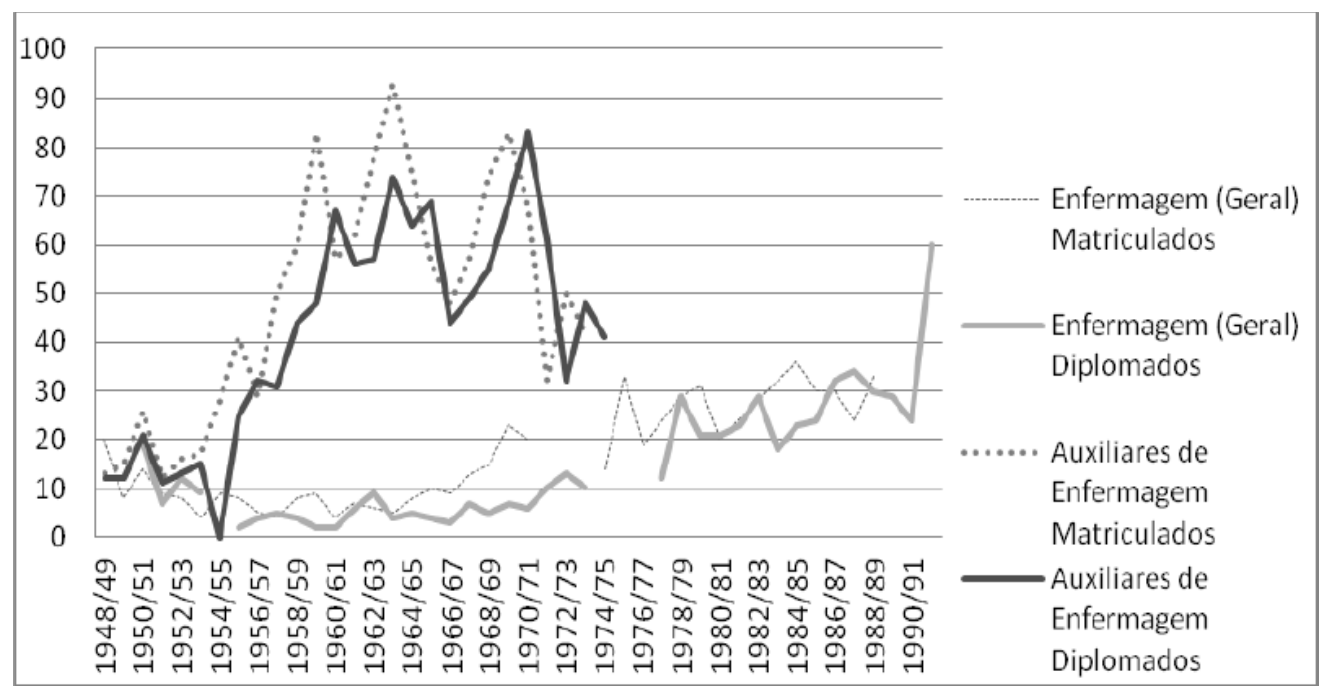

Fonte | AEECB - Livros de Matrículas dos Alunos Auxiliares de Enfermagem da Escola de Castelo Branco, Livros n 1,2,3 e 4 (1948-1974); Processos biográficos dos Alunos de Enfermagem (Geral) (1948-1988)

Como podemos verificar no Gráfico 1, a Escola de Enfermagem de Castelo Branco é um bom exemplo do argumento que acabamos de colocar. Entre 1948 e 1973/1974, formaram-se 1265 alunas/os no curso de Auxiliares de Enfermagem e, apenas, 221 alunas/os (de um conjunto global de 633, entre 1948 e 1988) no curso de enfermagem geral. Evidencia-se, ainda, que numa primeira fase (1948-1954) a escola registou um número equivalente de matrículas em ambos os cursos não havendo uma diferença muito significativa entre os cursos de auxiliares de enfermagem e de enfermagem geral. A instituição escolar procurou definir objetivamente o seu caminho do ponto de vista da formação que pretendia ministrar.

Numa segunda fase (1954-1973/1974) percebe-se que a escola aposta na formação de auxiliares de enfermagem, chegando mesmo, no início da década de 70 do século XX (anos letivos de 1971/1972-1973/1974), a não abrir qualquer curso de enfermagem, realçando-se uma aposta da escola 
na formação dos auxiliares, cujo período transitório de 5 anos, de acordo com a reforma do ensino de 1965, encontrava-se a terminar, apostando na necessidade e na última oportunidade de públicos com características específicas (baixas habilitações literárias, entre outras) poderem ainda frequentar os últimos cursos de auxiliares de enfermagem.

A terceira fase que identificamos prende-se com uma alteração estrutural da própria escola em articulação com exigências legais provenientes da tutela e da sociedade. A transformação da escola num estabelecimento de ensino público (1973), o fim do curso de auxiliares de enfermagem e as alterações resultantes da mudança de regime político (com a crescente força dos sindicatos) forçaram a escola a alterar a sua perspectiva formativa. Defendemos, portanto, que a escola de enfermagem albicastrense a partir de meados dos anos de 1970 construiu uma imagem de si capaz de dignificar e engrandecer o grupo que tinha como tarefa formar, acreditar e mandatar para o exercício da enfermagem no país, invertendo a lógica formativa minimalista que foi a sua opção numa primeira fase da sua vida de acordo, claro está, com as orientações do Estado.

A captação de público escolar constituiu outro indicador capaz de

22 nos elucidar sobre o impacto da escola do ponto de vista formativo. Como é evidente no Gráfico 2, a Escola de Enfermagem respondeu essencialmente a carências regionais e locais no domínio da assistência. Esta resposta, que, no fundo, encontra-se em observância com os objetivos iniciais propostos pelo fundador da instituição, também não facilitava o estabelecimento de relações com alunos de outras realidades, constituindo-se o próprio estabelecimento escolar quase como uma escola de segunda categoria, face, por exemplo, às faculdades de medicina que atraíam alunos de todo o país. 
Gráfico 2

A proveniência geográfica dos alunos da Escola de Enfermagem de Castelo Branco (1948-1988)

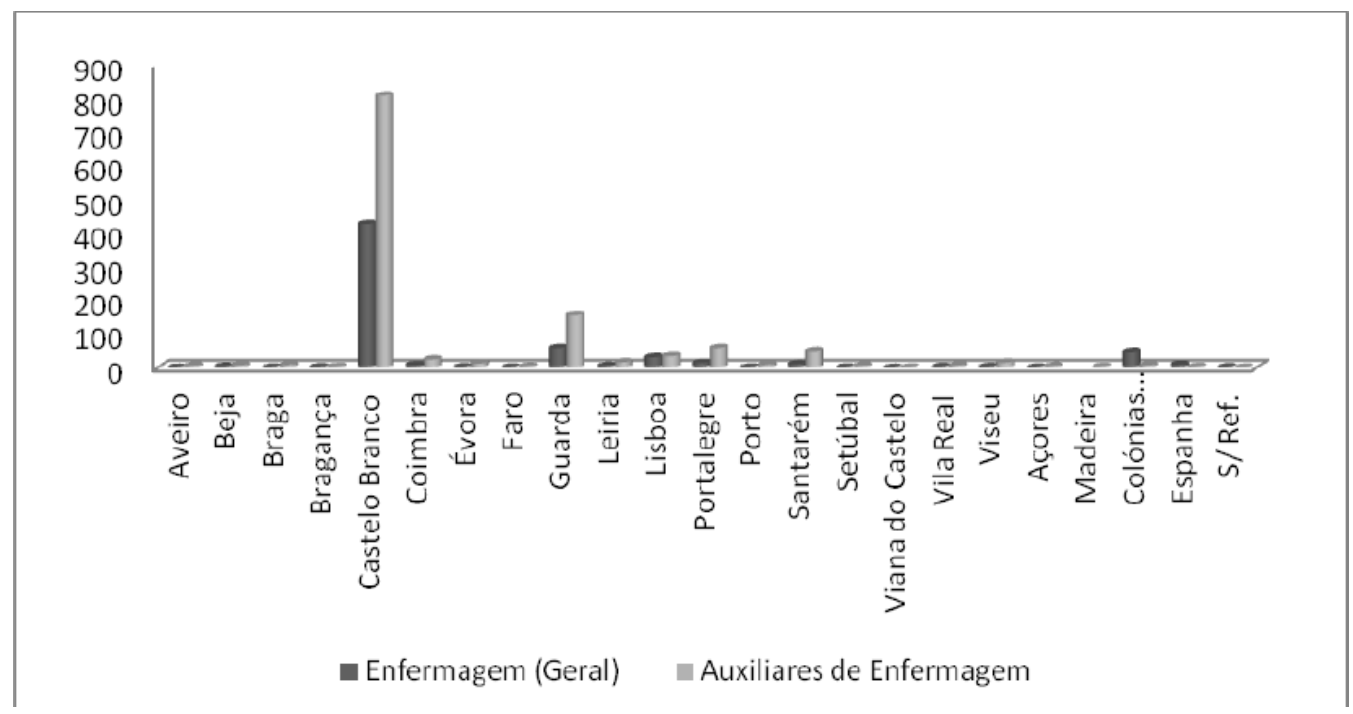

A proveniência geográfica dos alunos que frequentaram a Escola de Enfermagem de Castelo Branco/ Dr. Lopes Dias, embora com números diferenciados para os cursos em análise, assume proporções idênticas no que respeita à análise comparada que temos vindo a fazer. No período destacado observam-se essencialmente três distritos de maior proveniência de alunas/os para esta escola: o distrito de Castelo Branco, da Guarda e o de Portalegre. Em todos os casos sinalizados, evidencia-se o maior número de alunos do curso de auxiliar de enfermagem face ao curso de enfermagem. É de salientar o caso específico de Castelo Branco, local de implementação da Escola de Enfermagem, que sustenta a importância da instituição escolar essencialmente do ponto de vista regional e local. Neste caso observa-se que aos cursos de Auxiliar e de Enfermagem corresponde 64, 1\% e 67,7\% do universo escolar (por curso) respectivo. Logo a seguir surgem o distrito da Guarda e o distrito de Portalegre, territorialmente próximos da cidade de Castelo Branco. A escola ainda tinha alguma capacidade de captação de alunos dos distritos de Lisboa e Santarém, e a proximidade com a fronteira também favoreceu a 
frequência dos cursos desta escola por parte de alguns alunos com nacionalidade espanhola.

O grupo dos enfermeiros assume uma relação de proximidade com os elementos do género feminino. No Estado Novo o exercício da enfermagem hospitalar, pelo menos entre 1942 e 1963, encontrava-se reservado essencialmente para senhoras solteiras ou viúvas, sem filhos e com um comportamento irrepreensível. O processo de acreditação do público feminino para desenvolver esta atividade constituiu um mecanismo que interessava ao Estado e ao grupo dos médicos. Se o Estado, por um lado, "oferecia" a enfermagem como uma atividade para mulheres, por sua vez, iria permitir a algumas delas alguma autonomia económica. Não obstante, o mesmo Estado canalizava as mulheres para esta área de atuação, de acordo com os princípios gerais da época, porque além de poder exercer sobre elas maior controle que sobre os homens, estas serviriam como elementos vigilantes no interior da sociedade, em jeito de prolongamento da atividade privada para o espaço público. $\bigcirc$ Gráfico 3 apresenta esta realidade, uma vez que permite observar a evolução da procura da Escola de Enfermagem albicastrense por género.

Gráfico 3

A evolução geral do número de matriculados por género (1948 - 1988)

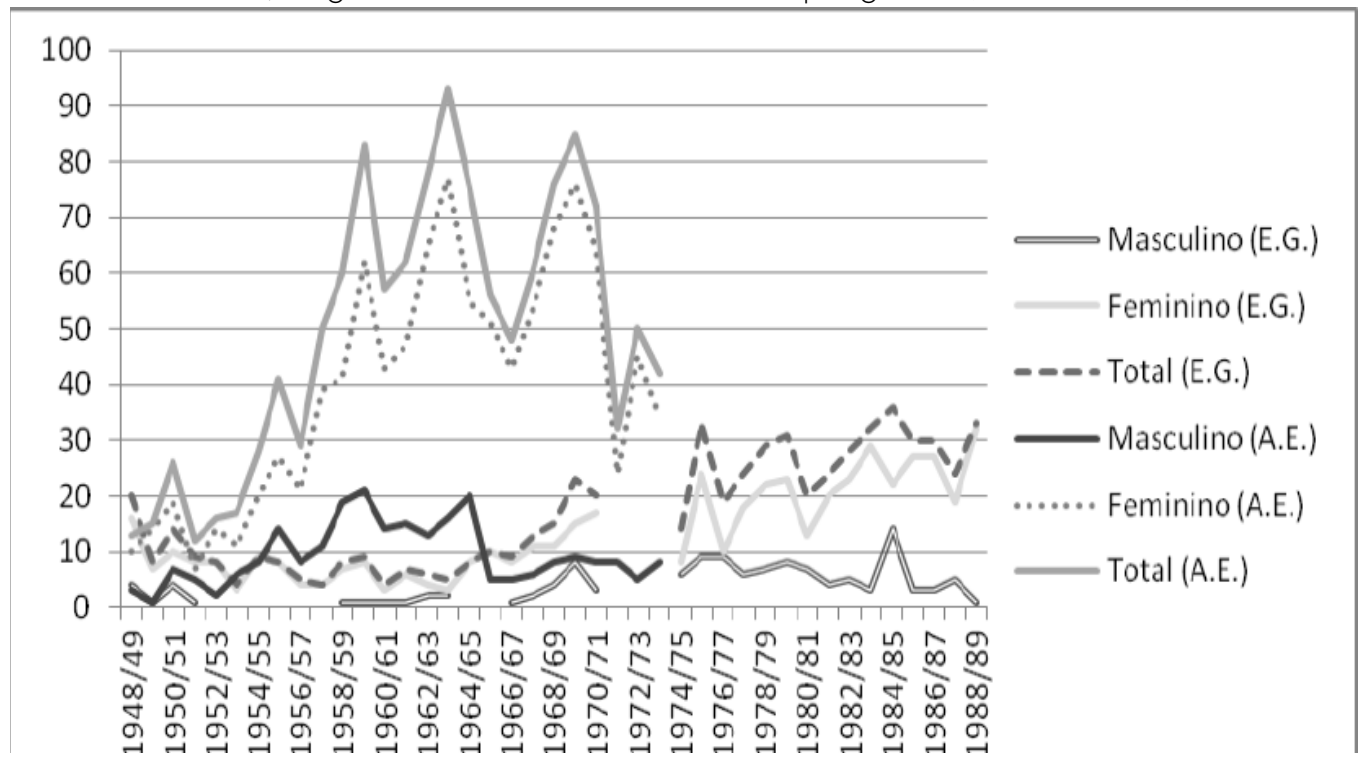


Fonte | AEECB - Livros de Matrículas dos Alunos Auxiliares de Enfermagem da Escola de Castelo Branco, Livros n 1,2,3 e 4 (1948-1974); Processos biográficos dos Alunos de Enfermagem (Geral) (1948-1988)

Este universo escolar era essencialmente feminino, uma característica que se prolongou do Estado Novo para o Portugal democrático (veja-se no gráfico o período político do Portugal democrático). A ideia de que a mulher devia assumir atividades que eram o prolongamento da esfera doméstica para a esfera pública não terminou com a revolução de 1974. No arco temporal em análise, em ambos os cursos de enfermagem (Auxiliares e Enfermagem Geral), verificamos a existência de cerca de $80 \%$ de elementos do género feminino. Mesmo que num ou outro ano se possa encontrar maior proximidade entre o número de alunos e de alunas isso nunca se manifestou em tendência. Projetando tanto pela frequência do Curso de Auxiliares de Enfermagem como pela do Curso de Enfermagem Geral não há dúvida que estamos perante uma profissão no feminino. De qualquer modo, o ser feminino antes ou depois de meados da década de setenta, não tem o mesmo significado relativamente à imagem da enfermagem, até porque a partir daí já não existia um Curso de Auxiliares de Enfermagem.

Um outro ângulo que pode ajudar na compreensão da representação social dos enfermeiros é a condição sócioprofissional das famílias de onde são provenientes os/as alunos/as dos cursos de enfermagem. No seguimento deste pensamento, parece-nos pertinente olharmos especificamente para o curso de Enfermagem Geral porque ele, ao contrário do curso de Auxiliares, permite uma análise durante um arco temporal maior e em mudança. Além disso, o curso de Enfermagem era aquele que formava de fato os futuros enfermeiros mandatados e acreditados para o exercício da enfermagem e que, por sua vez, tinham como papel a valorização da atividade e do grupo junto da sociedade e de outros grupos profissionais.

Quando analisamos os processos biográficos dos alunos desta instituição escolar, tomando como referência as atividades desenvolvidas pelo núcleo parental dos alunos que frequentaram o curso de enfermagem, percebemos que, no caso do elemento masculino (Pai), o principal setor económico de proveniência dos alunos da escola foi o terciário (38\%), seguido de perto pelo setor primário (33\%) e pelo setor secundário (29\%). No caso dos elementos do género feminino também encontramos $5 \%$ de mães que trabalhavam no setor 
terciário, 1\% no setor primário e secundário. Neste caso particular, destaca-se a sua condição de doméstica (93\%). $\bigcirc$ envio principalmente das suas filhas para a escola de enfermagem representava, em nosso entender, uma tentativa de lhes proporcionar alguma autonomia financeira que elas próprias não foram capazes de alcançar e ainda um mecanismo de mobilidade social da própria mulher numa sociedade de natureza patriarcal.

Aprofundando a perspetiva apresentada e realçando os grupos sociais de referência das alunas/os de enfermagem desta escola percebem-se vários aspetos que coincidem com que referimos anteriormente. Observemos o Gráfico 4:

\section{Gráfico 4}

Grupos sociais de recrutamento das/os alunas/os de Enfermagem Geral

(1948-1988)

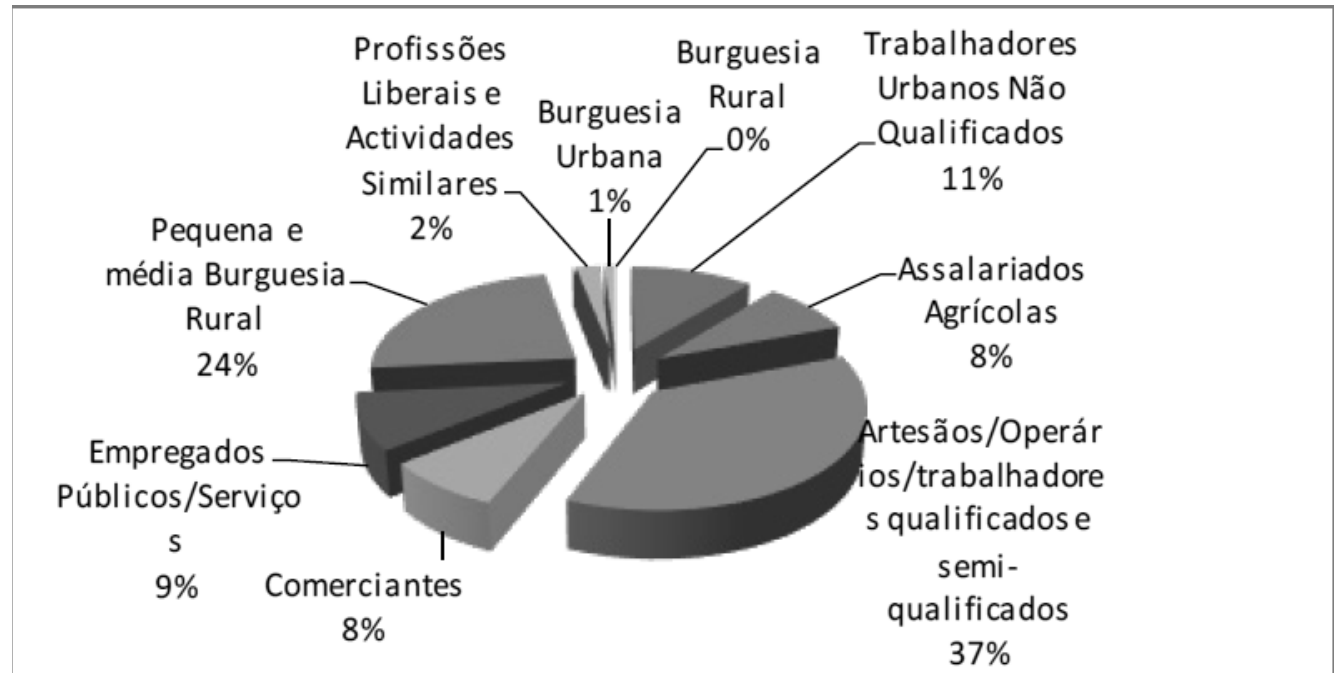

Fonte| AEECB - Processos biográficos dos Alunos do curso de Enfermagem Geral (1948-1988)

Neste estudo consideramos oito grupos de recrutamento de alunos matriculados na Escola de Enfermagem de Castelo Branco/Dr. Lopes Dias (1948-1988). A origem social dos alunos de enfermagem encontrava-se alocada sobretudo ao grupo que denominamos de "Artesãos/Operários/ Trabalhadores qualificados e semiqualificados" representando 37\% de 
indivíduos do corpo discente da escola albicastrense. Com 24\% surgiu o grupo da "Pequena e média burguesia rural". Logo depois, com $11 \%$, os "trabalhadores urbanos não qualificados", seguidos pelos "Empregados públicos/serviços" com 9\%, pelos "Assalariados Agrícolas" e pelo grupo dos "Comerciantes" com $8 \%$ cada um. No que respeita ao grupo dos "Profissionais liberais e atividades similares" os números são pouco significativos (2\%). O mesmo aconteceu com o grupo da "Burguesia rural/urbana" que apenas se encontra representada no conjunto dos estudantes de enfermagem por $1 \%$.

Percebe-se que os candidatos que procuraram a Escola de Enfermagem, e o Curso de Enfermagem Geral, não provinham de famílias com boa condição económica e social. Tudo indica que a Escola de Enfermagem de Castelo Branco/Dr. Lopes Dias, além de ter servido principalmente interesses regionais e locais, era constituída sobretudo por alunas (os) de classes médias baixas e baixas, sendo mesmo a maioria filhas de trabalhadores e muitas de trabalhadores não especializados, que procuravam a escola como uma forma de garantir alguma autonomia económica que, por exemplo, as suas mães não tinham alcançado. Vendo assim, embora o Estado acreditasse a enfermagem através das escolas específicas de formação de enfermeiros, durante muito tempo favoreceu uma política de recrutamento que devia situar a enfermagem numa situação de inferioridade e de submissão diante do poder do Estado e dos médicos.

A partir dos anos de 1970 o grupo ganhou um enorme impulso, do ponto de vista da sua profissionalização, e os seus elementos passaram a ser mais reconhecidos na sociedade, junto de outros grupos profissionais, voltando a assumir um papel de enorme relevância as escolas de enfermagem, os novos saberes mobilizados e as crescentes necessidades de pessoal especializado neste domínio, necessário à sociedade em processo de mudança, possibilitaram a acreditação de uma jurisdição socioprofissional designada de "cuidados de enfermagem", que constitui um dos aspetos principais no desenvolvimento do grupo dos enfermeiros no Portugal democrático. Todavia, a Escola de Enfermagem de Castelo Branco/Dr. Lopes Dias constitui apenas um retrato de uma realidade ampla que ainda está muito por estudar. 


\section{Considerações finais}

Ao incidirmos sobre uma Escola de Enfermagem de uma cidade do interior de Portugal, procuramos ver como se foi avançando no processo de construção da identidade profissional a partir da forma como nessa instituição de ensino se encarou o recrutamento dos seus alunos/as e os/as diplomou. Porque nos encontramos diante de uma Escola de Enfermagem que podemos definir como periférica, iá que à sua situação geográfica se juntava a de ter sido, durante muitos anos, uma instituição privada, pensamos que isso nos permite aquilatar melhor como se foi organizando a formação daqueles que prestavam atos de enfermagem e como se repercutia na generalidade do país o entendimento entre o Estado e os médicos sobre a condição do exercício da enfermagem e a construção da identidade desta profissão. Sendo, embora, uma escola do interior do país e privada ela não deixava de tender a integrar-se num dispositivo ao serviço do Estado e a servir uma lógica credencialista tal como se colocava ao espaço nacional.

Como já demos conta, as instituições escolares e formativas assumem uma importância assinalável no processo de construção das identidades profissionais enquanto elementos credencialistas e controladores da entrada de indivíduos para os grupos, representando o Estado nesse mesmo processo seletivo. Neste sentido, defendemos que o Estado exerce um papel relevante na construção das identidades profissionais na contemporaneidade, através dos processos formativos e institucionais. (LONGUENESSE, 1994). O credencialismo é uma figura chave na compreensão da construção de identidades de grupos profissionais na medida em que permite olhar o posicionamento do Estado em face de atividades e de profissões que disputam idênticos espaços de ação e de como ele reequaciona a sua posição quando as condições, cientifíicas, sociais, culturais, laborais colocam outras exigências. O Estado não apenas legitima a ação das instituições escolares, ele thes define o modo como elas devem influenciar a construção profissional dos grupos (RODRIGUES, 2002), desde logo a partir da forma como estabelecem o recrutamento dos alunos e enquadram a base social e cultural da família dos mesmos até à definição do percurso formativo que vai sendo instituído.

No caso da enfermagem, vendo a partir da Escola de Enfermagem de Castelo Branco, isso é muito evidente. O objetivo era selecionar aqueles que melhor correspondiam a um determinado perfil imposto pela tutela para, 
futuramente, se encontrarem mandatados para o exercício da enfermagem na sociedade. Do ponto de vista formativo assistimos, essencialmente durante o Estado Novo, a uma relevante presença do interesse médico nas escolas de enfermagem. Os médicos funcionavam como interlocutores do próprio Estado nos processos de formação, mas também nos de recrutamento, dos futuros enfermeiros. Eles constituíam o grupo privilegiado no campo da saúde, o único que tinha força para legitimar a ação do Estado neste âmbito. Este diálogo entre o Estado e os médicos garantiu, durante muitos anos, a presença do grupo nos processos de seleção e de formação dos futuros enfermeiros, influenciando decisivamente o seu desenvolvimento e reconhecimento socioprofissional. Esta articulação e a tentativa de manutenção do monopólio sobre o campo da saúde e do ato clínico tendeu a definir a enfermagem como atividade menor de auxiliar do médico.

Durante boa parte do Estado Novo, em Portugal, a atividade de enfermeiro caraterizava-se pela submissão, obediência e "espirito de missão". Estes princípios, construtores de uma "moral profissional", estabeleciam as diretrizes do que significava integrar um grupo como este. $\bigcirc$ poder de um Estado autocrático conjugado com uma conceção moral católica profundamente conservadora e a autoridade médica mesquinha e receosa da perda de privilégios definiram a enfermagem pela condição mínima do saber e pela primazia do agir abnegado e servil sob a ordem dos médicos a bem da sociedade. Não é por acaso que, na Escola de Enfermagem de Castelo Branco/ Dr. Lopes Dias, entre 1948 e 1973/4, formaram-se 1265 alunas/os no curso de Auxiliares de Enfermagem e, apenas, 221 alunas/os de Enfermagem Geral. Diante do quadro de assistência pretendido, estas profissionais podiam bem cumprir a missão que o médico lhe determinava, a preço mais baixo e da forma mais submissa. Por outro lado, mesmo as/os alunas/os do curso de Enfermagem Geral provinham de famílias pouco abastadas, o que indica certamente que a profissão que abraçavam não era especialmente considerada. A ausência de alunos/as provenientes de grupos sociais favorecidos, sendo que durante muitas décadas a região não contou com nenhuma instituição de ensino superior, também indicia que estes cursos e profissão não se encontravam nas prioridades das famílias com mais posses e mais cultas para lá colocar os seus filhos/as.

Todavia, a partir de meados dos anos de 1960, a enfermagem começou a ganhar um novo fôlego e aprofundou-se o processo de consolidação profissional da enfermagem portuguesa. Este processo carateriza-se pela 
construção de um Saber relacional e de fronteira, utilizando para o efeito os diferentes contributos das Ciências Sociais, Humanas e Comportamentais que assumiram um lugar de destaque nos planos de estudo das escolas de enfermagem e nos discursos dos próprios enfermeiros. Mas é, principalmente, a partir dos anos de 1970 do século XX que a enfermagem portuguesa vai ver uma identidade profissional mais respeitada, com maiores privilégios de grupo e socialmente reconhecida. $\bigcirc$ reforço identitário dos enfermeiros portugueses ficou a dever-se, em grande parte, ao papel credencialista das escolas de enfermagem, cumprindo as diretrizes da tutela. Através destas instituições, o Estado continuou a influenciar o processo de recrutamento dos candidatos às escolas de enfermagem, por exemplo, através da constituição de Comissões de Integração Escolar ou da alteração dos requisitos literários para a integração nas escolas. Vendo toda esta evolução, o Estado, interpretando e administrando as forças e as condições científicas e profissionais após a década de setenta, soube traduzir o reconhecimento da relevância da enfermagem portuguesa ao inserir a sua formação no ensino superior no ano de 1988.

A identidade socioprofissional dos enfermeiros portugueses encontra-se recheada de processos de negociação com avanços e recuos, onde o 30 Estado assume um lugar de destaque. Carateriza-se pela luta constante no sentido do reforço da sua jurisdição profissional e pela implementação de um Saber próprio. Alcançou maior autonomia, já no Portugal democrático, com a consolidação da ampliação dos "cuidados de enfermagem" à população, onde as novas exigências de recrutamento, nomeadamente as literárias, e a mobilização de novos saberes contribuíram para a afirmação da relevância deste domínio profissional relacional, de que as dinâmicas da Escola de Enfermagem de Castelo Branco podem constituir um exemplo. $\bigcirc$ credencialismo revela aqui um desenvolvimento complexo que o condiciona: por um lado, a ação do Estado e a negociação com a ordem médica disciplinando o exercício de uma atividade; por outro, uma evolução no contexto de um mesmo regime político, entretanto sujeito a pressões transnacionais; por fim, a pressão advinda do movimento associativo e a necessária negociação com o mesmo em simultâneo com a ampliação dos cuidados de saúde e a expansão do ensino superior. Tudo isto acabou por ter implicações no recrutamento, na frequência e na formação dos alunos das escolas de enfermagem bem como na condição e representação profissional dos enfermeiros/as. 


\section{Nota}

1 Arquivo da Escola de Enfermagem de Castelo Branco - Normas de Funcionamento Interno da Escola de Enfermagem de Castelo Branco (1976).

\section{Referências}

ABBOTT, Andrew. The system of professions: an essay on the division of expert labor. Chicago/London: The University of Chicago Press, 1988.

ABREU, Wilson Correia. Identidade, formação e trabalho: das culturas locais às estratégias identitárias dos enfermeiros. Coimbra (Lisboa): Formasau/Educa, 2001.

AMENDOEIRA, José. Uma biografia partilhada da Enfermagem: a segunda metade do Século XX. Coimbra: Formasau, 2006.

BRANCO, Manuel Leitão. $\bigcirc$ exercício legal de Enfermagem. Revista de Enfermagem, Lisboa, n. 1, p. $21-22,1953$.

COLLIÉRE, Marie-Françoise. Promover a vida - da prática das mulheres de virtude aos cuidados de enfermagem. Lisboa: SEP, 1989.

DUBAR, Claude; TRIPIER, Pierre. Sociologie des professions. Paris: Armand Colin, 1998.

ESCOBAR, Lucília. O sexo das profissões - género e identidade socioprofissional em Enfermagem. Porto: Edições Afrontamento, 2004. (Coleção Biblioteca das Ciências Sociais).

FARIA FILHO, Luciano Mendes de. Nação, identidade e educação na América Latina. In: ALVES, Claudia Maria Costa; MIGNOT, Ana Chrystina Venancio. (Org.). História e historiografia da Educação lbero-Americana: projetos, sujeitos e práticas. Rio de Janeiro: Quartet/ Faperj/SBHE, 2012.

FOLGADO, Joaquim. O lugar da ética e da auto-regulação na identidade profissional dos jornalistas. 2006. 667f. Tese (Doutoramento em Ciências da Comunicação) - Universidade do Minho, Instituto de Ciências Sociais, Braga, 2006.

FREIDSON, Eliot. Professional powers: a study of the institutionalization of formal knowledge. Chicago/London: The University of Chicago Press, 1986.

HENRIQUES, Helder Manuel Guerra. Formação, sociedade e identidade profissional dos Enfermeiros: a Escola de Enfermagem de Castelo Branco/Dr. Lopes Dias (1948-1988). 
2012. 600f. Tese (Doutoramento em Ciências da Educação - História da Educação) Universidade de Coimbra, 2012.

HENRIQUES, Helder Manuel Guerra. A Enfermagem em Portugal no Século XX: um retrato histórico. Revista Estúdios Humanistico, Léon, Universidad de Léon, n. 11, p. 31 1-329, 2012

HENRIQUES, Helder Manuel Guerra; FERREIRA, António Gomes. A Formação de enfermeiros e a afirmação da Enfermagem em Portugal: décadas de 40 a 60 . Cadernos de História da Educação, Uberlândia, v. 1 1, n. 2, jul./dez. p. 389-406, 2012 a.

HENRIQUES, Helder Manuel Guerra; FERREIRA, António Gomes. As normas e os valores na construção da identidade profissional da Enfermagem Portuguesa: décadas de 40 a 80 (séc. XX). Estudos do século XX, Coimbra, n. 12, p. 141-157, $2012 b$.

LARSON, Magali. The rise of professionalism - a sociological analysis. Berkeley/Los Angeles/London: University Of California Press, 1979.

LAWN, Martin. Os professores e a fabricação de identidades. Currículo sem Fronteiras, v. 1, n. 2, p. 117-130, jul./dez. 2001.

LONGUENESSE, Elisabeth. Introduction (Atelier 2 - État, institutions, pouvoirs et professions liberales). In: DUBAR, Claude; LUCAS, Yvette. (Eds.). Génese \& dynamique des groupes professionnels. Lille: Presses Universitaires de Lille, 1994.

MACDONALD, Keith. The sociology of the professions. 2. ed. London/Thousand Oaks/ New Delhi: Sage, 1999.

NÓVOA, António. Le temps des professeurs - analyse socio-historique de la profession enseignante au Portugal (XVIIle-XXe siécle). Lisboa: Instituto Nacional de Investigação Cientifica, 1987. (2 v.).

NUNES, Lucília Rosa Mateus. Um olhar sobre o ombro: Enfermagem em Portugal (18811998). Loures: Lusociência, 2003.

Ó, Jorge Ramos do; CARVALHO, Luís Miguel. Emergência e circulação do conhecimento psicopedagógico moderno (1880-1960) - estudos comparados Portugal- Brasil, Lisboa: Educa, 2009.

PITA, João Rui. Farmácia, Medicina e Saúde Pública em Portugal (1772-1836). Coimbra: Minerva Editora, 2009. 
PORTUGAL. Decreto-Lei no 31.913 , de 12 de março de 1942. Realça a importância do recrutamento de enfermeiras viúvas e sem filhos. Diário do Governo, Lisboa, 1942.

Decreto-Lei n 36. 219, de 10 de abril de 1947. Reorganiza o ensino da enfermagem. Diário do Governo, Lisboa, 1947.

Decreto $n^{\circ} 38.885$ de 28 de agosto de 1952. Reforma o ensino da enfermagem.

Diário do Governo, Lisboa, 1952.

Decreto-lei n 44.923 de 06 de março de 1963. Termina a obrigatoriedade de recrutamento de enfermeiras hospitalares solteiras. Diário do Governo, Lisboa, 1963.

Decreto-Lei $n^{\circ} 46.448$ de 20 de julho de 1965. Reforma do ensino da enfermagem, entre outros aspectos altera condições de admissão aos cursos. Diário do Governo, Lisboa, 1965.

Decreto-Lei n 48166 de 27 de dezembro de 1967. Constitui as carreiras de enfermagem hospitalar, saúde pública e de ensino. Diário do Governo, Lisboa, 1967.

Portaria $n^{\circ} 34 / 70$ de 14 de janeiro de 1970. Instaura o Regulamento geral das Escolas de Enfermagem. Diário do Governo, Lisboa, 1970.

Decreto n 346 de 30 de agosto de 1972. Cria o curso de promoção de auxiliares de enfermagem. Diário do Governo, Lisboa, 1972.

Portaria nº 674 de 13 de novembro de 1976. Regula os órgãos de gestão das escolas de enfermagem oficiais. Diário da República, Lisboa, 1976.

Decreto $n^{\circ} 98$ de 06 de setembro de 1979. Aumenta os requisitos de admissão ao curso de enfermagem para o curso complementar dos liceus ou equivalente. Diário da República, Lisboa, 1979.

Decreto-Lei n 480 de 23 de dezembro de 1988. Integra a enfermagem no Sistema Educativo Nacional, ao nível do subsistema de ensino superior politécnico. Diário da República, Lisboa, 1988.

RODRIGUES, Maria de Lurdes. Os Engenheiros em Portugal - profissionalização e protagonismo. Oeiras: Celta Editora, 1999.

RODRIGUES, Maria de Lurdes. Sociologia das profissões. 2. ed. Oeiras: Celta Editora, 2002. 
SILVA, Ana Maria Costa. Formação e construção de identidades - um estudo de caso centrado numa equipa multidisciplinar, 2005. 406f. Tese (Doutoramento em Educação) Universidade do Minho, Instituto de Educação e Psicologia, Braga, 2005.

SILVA, Helena Rodrigues., Soigner à l'hôpital: histoire de la profession infirmière au Portugal (1886-1955). 2010. 601f. Tese (Doutoramento em História Contemporânea) - Ecole de Hautes Études en Sciences Sociales (Paris), Universidade do Minho, Braga/Paris, 2010.

SOARES, Maria Isabel. Da blusa de brim à touca branca - contributo para a História do Ensino de Enfermagem em Portugal (1880-1950). Lisboa: Educa/Associação Portuguesa de Enfermeiros, 1997.

Prof. Dr. António Gomes Ferreira Universidade de Coimbra

Faculdade de Psicologia e Ciências da Educação Grupo de Pesquisa | GRUPOEDE - Centro de Estudos Interdisciplinares do Século XX | CEIS2O

E-mail|antonio@fpce.uc.pt

Prof. Dr. Helder Manuel Guerra Henriques Instituto Politécnico de Portalegre

Escola Superior de Educação

Grupo de Pesquisa | GRUPOEDE - Centro de Estudos Interdisciplinares do Século XX | CEIS2O | Universidade de Coimbra E-mail |henriqueshelder@gmail.com

Recebido 4 mar. 2013

Aceito 7 maio 2013 